21 Surawitz CM, Myerson D. Self-limited cytomegalovirus colitis in immunocompetent individuals. Gastroenterolog 1988;94:194-9.

22 Cunningham $\dot{M}$, Cantoni L, Humair L. Cytomegalovirus primoinfection in a patient with idiopathic proctitis. $A m \mathcal{F}$ Gastroenterol 1986;81:586-8.

23 Guttman D, Raymond A, Gelb A, Ehya H, Mather V, Mildvan $D$, et al. Virus-associated colitis in homosexual men: two van $\mathrm{D}$, et al. Virus-associated colitis in homosexual

24 Balthazar EJ, Megibow AJ, Fazzini E, Opulencia J, Engel I. Cytomegalovirus colitis in AIDS: Radiographic findings in Cytomegalovirus colitis in AIDS: Radiog
11 patients. Radiology 1985;155:585-9.

25 Powell RD, Warner NE, Levine RS, et al. Cytomegalic inclusion disease and ulcerative colitis. Report of a case in a young adult. $A m \mathcal{F}$ Med 1961;30:334-40.

26 Wong TW, Warner NE. Cytomegalic inclusion disease in adults. Report of 14 cases with review of the literature. Arch Pathol. 1962;74:403-22.
27 Levine RS, Warner NE, Johnson CF. Cytomegalic inclusion disease in the gastrointestinal tract of adults.Ann Surg 1964 159:37-48.

28 Keren DF, Milligan FD, Strandberg JD, Yardley JH. Intercurrent cytomegalovirus colitis in a patient with ulcerative colitis. Fohns Hopkins Med f 1975;136:178-82.

29 Dent DM, Duys PJ, Bird AR, et al. Cytomegalovirus infection of the bowel in adults. $S$ Afr Med $\mathcal{f} 1975 ; 49: 669-$ infectic

30 Sidi S, Graham JH, Razvi SA, et al. Cytomegalovirus infecSidi S, Graham JH, Razvi SA, et al. Cytomegalovirus infec-
tion of the colon associated with ulcerative colitis. Arch Surg

31 Swarbrick ET, Kingham JGC, Price HL, et al. Chlamydia, cytomegalovirus and Yersinia in inflammatory bowel disease. Lancet 1979;2:11-2.

32 Scullard GH, Smith CI, Merigan TC, et al. Effects of immunosuppressive therapy on viral markers in chronic active hepatitis B. Gastroenterology 1981;81:987-91.

\title{
Familial cavernous angiomas masquerading as multiple sclerosis
}

\section{Royal Victoria Infirmary, Queen Victoria Road, \\ Newcastle upon Tyne NE1 4LP, UK \\ Department of \\ Neurology \\ C F Dougan \\ N E F Cartlidge \\ D J Burn \\ Department of \\ Radiology \\ A Coulthard \\ Correspondence to \\ Dr DJ Burn}

Accepted 10 March 1998

\author{
C F Dougan, A Coulthard, N E F Cartlidge, D J Burn
}

\begin{abstract}
Summary
We report here two cases of cavernous angioma, in the proband and her father, with quite different clinical presentations. The proband presented with a brainstem syndrome, mimicking multiple sclerosis, while the father had a history of mild epilepsy. Both patients were managed conservatively. The cases also demonstrate the utility of magnetic resonance imaging in the diagnosis of cavernous angioma.
\end{abstract}

Keywords: cavernous angiomas; multiple sclerosis; magnetic resonance imaging

Cavernous angiomas (also known as cavernomas and cavernous haemangiomas) are a form of intracranial vascular malformation that are reported to affect $0.5 \%$ of the population. ${ }^{1}$ In up to $75 \%$ of patients the lesions are multiple. They are characterised by collections of large, abnormal vascular spaces without intervening brain parenchyma. ${ }^{2} \mathrm{Up}$ to $50 \%$ of patients with cavernous angiomas have a familial form of the disorder which is inherited in an autosomal dominant mode, with incomplete clinical penetrance. ${ }^{1}$ The familial form may be more frequent in the Hispanic population. ${ }^{3}$ Recent genetic studies have identified linkage of this trait to chromosome 7q11.2-q21 in some families. ${ }^{12}$ Although cavernous angiomas are rarely life-threatening, they may cause significant morbidity related to their size and location.

\section{Case reports}

Case 1

A 19-year-old, right-handed woman was admitted in 1988 with a 5-day history of progressive neurological dysfunction. At the onset she had awoken with numbness of the left side of her tongue, which spread over 24 hours to affect the whole left side of her face. She sub- sequently developed horizontal diplopia, worse on right lateral gaze, and incoordination, with a tendency to fall to the left. On the day prior to admission she had developed patchy sensory disturbance in her left arm and leg. Her medical history was unremarkable. She was taking the oral contraceptive pill. She was one of four siblings and her father had epilepsy.

On general medical examination the only findings of note were haemangiomatous lesions on the dorsum of her left hand, left calf and right thigh. Neurologically, her gait was ataxic. Fundoscopy was normal, but there were bilateral partial sixth nerve palsies, and upbeat nystagmus on upgaze. There was a left sensory trigeminal neuropathy and mild subjective blunting of hearing on the left side. In the limbs there was a mild left-sided pyramidal weakness, with subjective reduction of light touch and pin-prick distally in the left arm and leg. A diagnosis of demyelination was suspected. Visual evoked potentials were normal. A computed tomography (CT) scan of the cranium revealed two small high-density lesions in the right side of the brainstem and left putamen, thought to represent areas of haemorrhage. Cerebrospinal fluid (CSF) examination was entirely normal, with absent oligoclonal bands. The patient's condition spontaneously improved, and follow-up CT brain scan 2 weeks later showed considerable resolution of the high density lesions.

Eight months later she was re-admitted with a relapse comprising similar brainstem symptoms and signs, following a minor acute neck sprain. Cranial magnetic resonance imaging (MRI) scan revealed three separate lesions typical of cavernous angiomas, including a large lesion in the tegmentum of the midbrain, eccentrically located to the right (figure).

The patient has been managed conservatively to date. She has suffered a number of relapses referable to the brainstem cavernous angioma but has recovered to normal 

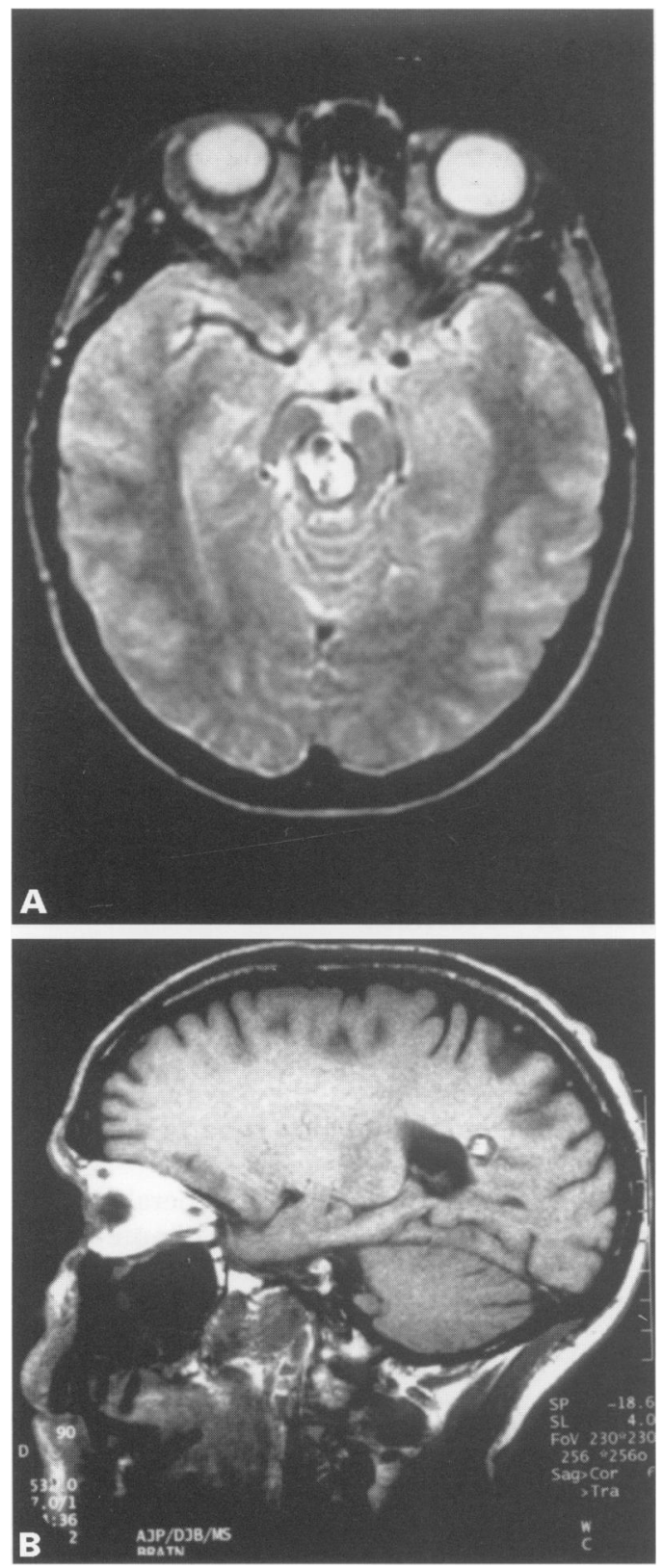

Figure (A) Axial T2-weighted image at the level of the midbrain, showing large cavernous angioma with very hyperintense central signal and peripheral hypointensity; (B) sagittal T1-weighted image from same patient showing separate lesion adjacent to the posterior horn of the lateral ventricle. Both the central signal hyperintensity and the peripheral hypointensity are typically less marked than on T2-weighted images

neurological function after each of these. Repeat MRI scans have shown increase in size of the lesions, with signal changes in keeping with haemosiderin deposition, due to recurrent haemorrhage.

Case 2

This 54-year-old man, the father of Case 1, subsequently presented in 1996 with a history suggestive of right-sided transient ischaemic attacks. He had a history of extensive peripheral vascular reconstructive surgery and was an ex-smoker. He also reported two generalised seizures, the last of which was in 1985 . He was still taking sodium valproate at the time of presentation.

\section{Learning/summary points}

- intracranial cavernous angiomas may be asymptomatic or present with seizures, focal neurological disturbance, headaches or haemorrhage

- up to $50 \%$ of cases are familial and inherited as an autosomal dominant trait

- varied presentation and often indolent clinical course may lead to diagnostic delay or misdiagnosis

- MRI scanning is the diagnostic method of choice

On examination, he was normotensive, but peripheral pulses were weak in the legs. General medical and neurological examinations were otherwise normal.

A CT brain scan showed areas of increased density in the right temporal lobe and another in the right fronto-parietal region with no evident mass effect. An MRI brain scan subsequently showed five separate lesions all having the typical signal characteristics of cavernous angiomas. The patient has been managed conservatively to date.

\section{Discussion}

These cases illustrate the different ways in which cavernous angiomas may present. Symptomatic patients typically present between the ages of 20 and 40, although symptoms can begin at any age. Focal neurological deficits may occur in $10-35 \%$ of cases and when angiomas are located in the brainstem, a mixed diagnosis of multiple sclerosis has been reported in up to $10 \%$ of patients. ${ }^{4}$ Vrethem et al reported the case of a 35-year-old man with symptoms mimicking multiple sclerosis who went 15 years before MRI scanning revealed a brainstem cavernous angioma. ${ }^{4}$ This case was exceptional, however, because the patient had oligoclonal bands in the cerebrospinal fluid; such a finding would normally be supportive of multiple sclerosis and has not been reported in any other case of cavernous angioma (including our Case 1).

Epilepsy is the more common clinical presentation of cavernous angiomas, occurring in between $30 \%$ and $50 \%$ of patients. ${ }^{1}$ Seizures can be focal, generalised, or both. ${ }^{5}$ Other clinical presentations include headaches $(20-30 \%)$, and recurrent haemorrhages, more often occult. ${ }^{15}$ In several cases the lesions may be asymptomatic and only detected incidentally. ${ }^{23}$ CT brain scanning has a $10 \%$ false negative rate, while angiography may be normal in about one-third of reported cases with cavernous malformations. ${ }^{67}$ The investigation of choice is MRI scanning, which has good sensitivity and specificity. Cavernous angiomas have typical appearances on MRI which are considered diagnostic. These include central signal hyperintensity and prominent peripheral signal hypointensity on T1- and T2-weighted sequences corresponding to subacute haemorrhage and haemosiderin, respectively. There is usually no mass effect or oedema, no feeding 
arteries or draining veins and no enhancement after intravenous contrast agent. ${ }^{8} \mathrm{MRI}$ is also safe for monitoring patients with cavernous angiomas, and is able to demonstrate the dynamic state of the lesions, with new lesions appearing in nearly $30 \%$ of patients at 2.2 years follow-up in one study. ${ }^{3}$

1 Notelet L, Chapon F, Khoury S, et al. Familial cavernous malformations in a large French kindred: Mapping of the gene to the CCM1 locus on chromosme 7q. F Neurol Neurosurg Psychiatry 1997;63:40-5.

2 Gunel M, Awad IA, Anson J, Lifton RP. Mapping a gene causing cerebral cavernous malformation to 7q11.2-q21. Proc Natl Acad Sci USA 1995;92:6620-4.

3 Zabramski JM, Wascher TM, Spetzler RF, et al. The natural history of familial cavernous malformations: Results of an ongoing study. F Neurosurg 1994;80:422-32.

4 Vrethem M, Thuomas K-A, Hillman J. Cavernous angioma of the brainstem mimicking multiple sclerosis. N Engl $₹$ Med 1997;336:875-6.
The management of cavernous angiomas ranges from observation, with treatment of seizures along conventional lines where necessary, to surgical extirpation for accessible lesions that produce repetitive or progressive symptoms. Prophylactic resection of asymptomatic lesions is not indicated.

5 Tagle P, Huete I, Méndez J, de Villar S. Intracranial cavernous angioma: presentation and management. $f$ Neurosurg 1986;64:720-3.

6 Rigamonti D, Hadley MN, Drayer BP, et al. Cerebral malformations: Incidence and familial occurrence. $N$ Engl f Med 1988;319:343-7.

7 Rigamonti D, Drayer BP, Johnson PC, Hadley $M N$, Zabramski J, Spetzler RF. The MRI appearance of cavernous malformations (angiomas). $\mathcal{F}$ Neurosurg 1987;67: 518-24.

8 Atlas SW, Hurst RW. Intracranial vascular malformations and aneurysms. In: Atlas SW, ed, Magnetic resonance imaging of the brain and spine, 2nd edn. Philadelphia: Lippincott Raven, 1996; ch 12, p521. 